\title{
International survey and surgeon's preferences in diagnostic work-up towards treatment of anterior shoulder instability
}

\author{
Hanneke Weel ${ }^{3} \cdot$ Wouter Tromp $^{4} \cdot$ Peter R. Krekel $^{2} \cdot$ Pietro Randelli $^{5}$. \\ Michel P. J. van den Bekerom ${ }^{1} \cdot$ Derek F. P. van Deurzen $^{1}$
}

Received: 18 October 2015/Published online: 14 March 2016

(c) The Author(s) 2016. This article is published with open access at Springerlink.com

\begin{abstract}
Purpose Recurrent anterior shoulder instability after surgical treatment can be caused by bony defects. Several diagnostic tools have been designed to measure the extent of these bony lesions. Currently, there is no consensus which measurement tool to use and decide which type of surgery is most appropriate. We therefore performed an evaluation of agreement in surgeons' preference of diagnostic work-up and surgical treatment of anterior shoulder instability.

Methods An international survey was conducted amongst orthopaedic shoulder surgeons. The survey contained questions about surgeons' experience, clinical and radiological examination and the subsequent treatment for anterior shoulder instability. Descriptive statistics were used to present the data, and percentages of responding surgeons were calculated.

Results The questionnaire was completed by 197 delegates from 46 countries. $55 \%$ of the respondents think evidence in current literature is sufficient on diagnostic
\end{abstract}

Hanneke Weel

h.weel@amc.nl

1 Department of Orthopaedics and Traumasurgery, Onze Lieve Vrouwe Gasthuis, Oosterpark, 91091 AC Amsterdam, The Netherlands

2 Clinical Graphics, Delft, The Netherlands

3 Department of Orthopaedics, Academic Medical Center, Meibergdreef 9, 1105 AZ Amsterdam, The Netherlands

4 BovenIJ Hospital, Amsterdam, The Netherlands

5 2nd Department of Orthopaedics, IRCCS Policlinico San Donato, Università degli Studi di Milano, Via Mangiagalli 30, San Donato Milanese, 20097 Milan, Italy work-up for anterior shoulder instability. Anamnestic, number of dislocations was most frequently asked (by $95 \%$ of respondents), the most frequently used test is the apprehension test (91\%). For imaging, conventional X-ray in various directions was most performed, followed by MR arthrography and plane CT scan respectively. The responding surgeons perform surgery (labrum repair or Latarjet) in $51 \%$ of the patients. A median of $25 \%$ glenoid bone loss was given by the respondents, as cut-off from when to perform a bony repair.

Conclusion Many different diagnostic examinations for assessing shoulder instability are used and a high variety is seen in the use of diagnostic tools. Also no consensus is seen in the use of different surgical options (arthroscopic and open procedures). This implies the need for more research on diagnostic imaging and the correlation with specific subsequent surgical treatment.

Level of evidence Survey, level of evidence IV.

Keywords Recurrence $\cdot$ Anterior instability $\cdot$ Shoulder joint $\cdot$ Diagnostic $\cdot$ Survey

\section{Introduction}

Post-traumatic anterior glenohumeral instability is the most common type of shoulder instability with a reported prevalence of $2 \%$ [10]. During dislocation of the shoulder damage may occur to capsule, ligaments, labrum or bony structures such as the glenoid rim and humeral head [8]. The extent to which these bony defects of the glenoid rim occur is variable $[5,22]$ and so is the location and size of the Hill Sachs defect $[3,5]$. Currently it is believed that recurrent instability is contributed by interplay of these existing bony defects $[5,25,28]$. 
Several methods have been developed to quantify the position and size of bony defects $[22,28]$ to predict the risk of recurrence [2]. Depending on this preoperative (or intraoperative) quantification the type of surgical treatment is chosen. Different surgical approaches have been proposed, each specifically aiming at correction of one or more of these defects. Although arthroscopic Bankart repair has evolved to a technically feasible procedure with minimal co-morbidity, relatively high recurrence rates have been published $[9,12$, 26]. The traditional bony procedures such as these according to Latarjet have been reported to have lower recurrence rates $[9,12]$. However, these procedures might have higher complication risks and also are not without failures [6]. In the last decade there have been an increasing number of reports on bony procedures performed in an arthroscopic fashion [4, 7]. However, current literature is still inconclusive when, with what amount of bone loss, to perform a soft tissue repair or a bony procedure.

To determine in which way orthopaedic surgeons assess shoulder instability and on what basis they choose for a specific therapeutic strategy, an international survey on clinical management of anterior shoulder instability was held at the European Society of Sports Traumatology, Knee Surgery and Arthroscopy (ESSKA) congress 2014. The aim of the survey is to investigate opinions of specialists in shoulder surgery on clinical decision-making when facing patients with anterior shoulder instability. The hypothesis is that there is a wide variation in clinical practice concerning diagnosing and treatment of anterior shoulder instability.

\section{Materials and methods}

An expert team of two senior orthopaedic shoulder surgeons, one $\mathrm{PhD}$ candidate and one technical engineer, conducted an English questionnaire about anterior shoulder instability. The questionnaire was about the use of preoperative clinical examination, radiological assessment and treatment strategy of anterior shoulder instability. The questionnaire consisted of thirteen questions of which three open and ten multiple choice questions divided in three subtopics: clinical assessment, imaging and therapeutic management in anterior shoulder instability. Distributed questionnaire is added in Appendix.

The survey was distributed during the ESSKA congress in Amsterdam in May 2014. Paper questionnaires were distributed during and after sessions concerning shoulder instability related topics.

Notable strings were reported. Categorical data and dichotomous variables were summarized as percentages of the responding surgeons.
Table 1 Respondent characteristics

\begin{tabular}{lll}
\hline & & $N(\%)$ \\
\hline Country & Europe & $117(59)$ \\
& & West (55), East \\
& & $(45)$ \\
& Russia & $4(2)$ \\
& Middle east & $32(16)$ \\
& Asia & $17(9)$ \\
& Other (i.e. South Africa, South & $23(12)$ \\
& America) & \\
ASI patients per & Unknown & $4(2)$ \\
year & $20-50$ & $27(14)$ \\
& $50-100$ & $71(36)$ \\
& $>100$ & $58(29)$ \\
& $41(21)$
\end{tabular}

ASI anterior shoulder instability, $N$ number, \% percentage

\section{Results}

Of the surgeons participating in the shoulder lecture during the 9th ESSKA congress, 197 delegates from 46 different countries completed the survey (Table 1). Most $(59 \%)$ of the surgeons were from Europe. The median number of shoulder instability patients seen per surgeon per year was 50 ranging from 5 to 350 patients. Hereof, a median of 20 patients (range 0-200) was surgically treated.

\section{Assessment of the presence of anterior shoulder instability}

During patient evaluation in the outpatient clinic, most frequently evaluated patient characteristics by the surgeons are shown in graphically shown in Fig. 1.

During physical examination, the majority of surgeons perform the sulcus sign test $(76 \%)$, apprehension test $(91 \%)$ and relocation test $(66 \%)$. The hyperabduction test of Gagey is less frequently used (48\%), see Fig. 2.

\section{Shoulder instability and imaging}

Conventional X-rays were taken anterior posterior (65\% of all respondents) and/or the Bernageau view (56\%) and less often the Velpeau view (11\%). The MR arthrography was used by $54 \%$ respondents, plane CT scan was used by $27 \%$ respondents. Imaging modalities were used by $65 \%$ of surgeons to quantify the Hill Sachs defect, $85 \%$ of the respondents measure glenoid bone loss with either plane MR (26\%) and/or CT scan (61\%). Nine respondents (5\%) use both MR and CT scan for measuring bone loss. 


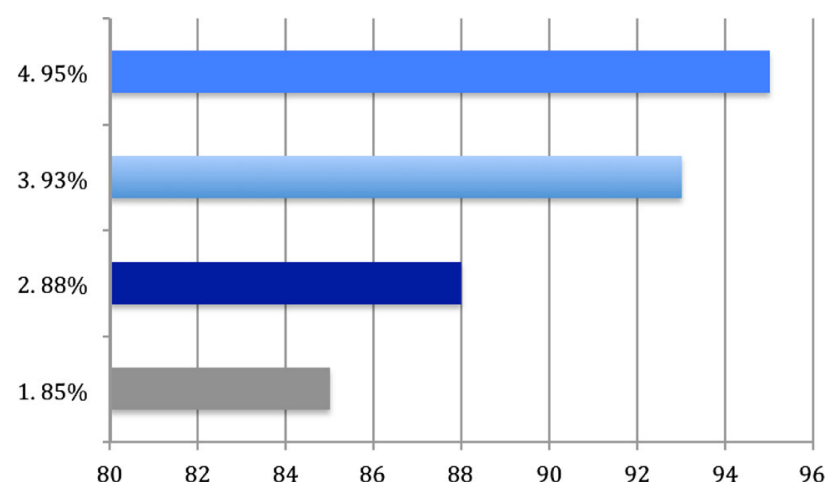

Fig. 1 Most asked patient characteristics. 1 Profession, 2 performing sports, 3 traumatic event, 4 number of dislocations

A total of $17 \%$ of respondents do not measure bone loss. Different methods of calculation methods are used to assess percentage of bone loss: Sugaya [22] is used in $39 \%$, the Index X [17] in $22 \%$, ITOY [11] in $21 \%$ and Hardy [19] in $14 \%$.

\section{Therapeutic management of shoulder instability}

About half of the respondents (55\%) think sufficient knowledge and evidence on the decision method for an operative treatment of shoulder instability is available in current literature and guidelines. Approximately half of the patients seen in clinic with anterior shoulder instability were surgically treated: $51 \%$ (range 0-100\%).

$64 \%$ also measures the Hill Sachs lesion, to perform a remplissage [21], where $33 \%$ is not doing (3\% is unknown). The arthroscopic labrum repair and the Latarjet procedure were the most frequent procedures performed by the respondents (respectively 94 and $54 \%$ ). To determine the most optimal treatment regime, $50 \%$ of respondents used the ISIS [2, 23] guidelines, $32 \%$ is not using guidelines and the other $18 \%$ of respondents used personal experience, plain patient characteristics, percentage of bone defects and Stanmore guidelines. Based on a median of $25 \%$ (rang 10-85\%) bone loss of the glenoid, the respondents changed their approach from soft tissue repair into a bony procedure.

Of the responding surgeons, $61 \%$ have trained or are planning to perform an arthroscopic Latarjet procedure in future, $8 \%$ is already performing it.

\section{Discussion}

An international survey on clinical management of anterior shoulder instability was held at the ESSKA congress 2014. The aim of the survey was to evaluate opinions of specialist in shoulder surgery on clinical decision-making when facing patients with anterior shoulder instability. Following our hypothesis, the survey showed a wide variation in clinical practice in patients suspected of having anterior shoulder instability. Just over half of the respondents of our survey $(55 \%)$ believe that sufficient knowledge on the decision method for an operative treatment of shoulder instability is available in current literature and guidelines.

Many clinicians believe that assessing stability of the shoulder is challenging because of the complexity of the combined motions of degree of the glenohumeral and scapulothoracic joints [1]. Based on our survey, type of profession, type of sports practiced, prior shoulder trauma and number of dislocations were seen as most helpful anamnestic characteristics in guiding treatment strategy. van Kampen et al. [27] concluded that the most important predictors for recurrence were young age, previous shoulder dislocation and a sudden onset of complaints. A more recent meta-analysis [18] showed that sex, age at initial dislocation, time from initial dislocation, greater tuberosity
Fig. 2 Most performed physical examination tests given in percentages $(\%)$

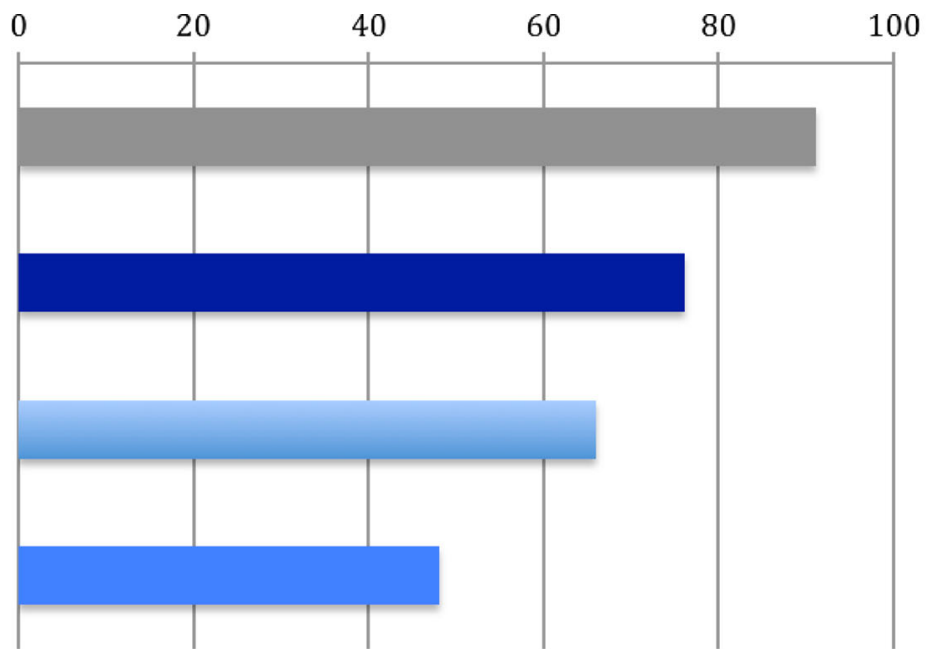

\section{1. apprehension}

2. sulcus sign

3. relocation

4. Gagey (hyperabduction) 
fractures and hyperlaxity were risk factors with high evidence for recurrent instability.

A variability of clinical tests has been described to identify glenohumeral translation (determine laxity) or to provoke recurrence of the symptoms of glenohumeral instability (provocation tests) [24]. Our survey shows that the apprehension test is the most frequently used provocation test $(91 \%)$. The accuracy of shoulder instability tests are, according to a review of Luime et al. [16], not high; a solely apprehension test was found to be of limited value. Combining the apprehension test with the relocation test and the anterior release test gives the highest accuracy. The study of Lo et al. examined three different provocation tests on patients with possible (anterior) shoulder instability [13]. Out of the three tests, the surprise test had the highest accuracy. In patients who had a feeling of apprehension during the apprehension-, relocation- and surprise test, the mean positive and negative predictive values were $94 \%$ and $72 \%$, respectively [13]. The study of van Kampen et al. [27] found an overall accuracy that varied between 80 and $88 \%$ (apprehension $82 \%$, relocation $85 \%$, release $86 \%$, hyperabduction $81 \%$ ).

Our survey showed an average of $51 \%$ of patients having shoulder instability undergoing surgical treatment. It was beyond the reach of our survey that the surgeons who filled out the questionnaire probably treat different populations; e.g. athletes, elderly patients. Nevertheless, a review of Longo et al. [14] showed results favouring a surgical approach above a conservative treatment with a smaller recurrence rate after surgery. Especially young adults, with high demanding sports or job activities, seem to benefit from an early surgical treatment of shoulder instability [14].

The vast majority of $94 \%$ of the surgeons participating in our survey perform arthroscopic labrum repair on patients with shoulder instability compared to only $12 \%$ who perform an open Bankart procedure. Due to the manner of questioning, we cannot state that the open Bankart repair was the preferred primary treatment only for certain cases or used when there was persisting instability after arthroscopic treatment. In addition, $57 \%$ of surgeons perform an open Latarjet procedure and $8 \%$ perform the arthroscopic Latarjet technique. A noteworthy amount of studies have been conducted on the comparison between open and arthroscopic repair in shoulder instability $[6,9,12]$. Lately some epidemiological parameters are reviewed to be significantly associated with recurrence rate after Bankart repair [20].

On a median of $25 \%$ bone loss of the glenoid, respondents changed their approach from soft tissue repair into a bony procedure. Though this percentage had a range of $10-85 \%$, showing that there is still uncertainty about this cut-off value. This is in accordance with the literature [15] that is also showing the existing uncertainty about with which size of the Bankart or Hill Sachs bone defect which procedure to perform. A possible explanation, supported by this survey, is the number of different methods available how to determine this bone loss [2, 11, 17, 19, 22, 28]. Moreover recurrence rates might not be only related to choice of surgical treatment only; it can also be the result of suboptimal interpretation of the performed diagnostic strategy, protocol, and quantifying bone loss resulting in differences in subsequent treatment. Additionally, softer parameters like patients preferences can also interfere with choice of treatment and therefore cause variation. Another consideration is that in finding best diagnostic options and subsequent therapeutic regiments in patients with shoulder instability, one should use evidence-based medicine combined with clinical experience in surgical management and the patients' wish. Due to the lack of conclusive evidence on the management of shoulder instability, surgeons have to fall back on lower evidence levels and clinical experience, which can result in variable strategies like found in this research. This and also the way of stating the questions caused a fail in showing nuances and could have had provoked recall bias in our respondents.

Because of the high number of surgeons out of different countries that participated in our survey, we think we found evidence for adopting our hypothesis that high variety in diagnostic work-up towards treatment of shoulder instability (still) exists. Therefore, to improve international consensus and thus the diagnosing and treatment of patients with shoulder instability, we recommend more research especially on this topic. Future research has to focus on quantifying bone loss and finding the exact cut-off when to perform "bony" surgery. This should improve treatment possibilities and thus satisfaction rates with fewer recurrences in patients with shoulder instability.

\section{Conclusion}

For assessing anterior shoulder instability, a great amount of diagnostic strategies are available. In this survey a high variety in the use of these diagnostic tools is seen amongst surgeons. Also no consensus is observed in the use of therapeutic options and with which amount of bone loss choosing the right strategy in shoulder instability. A suggested solution would be an updated international consensus for using accurate diagnostic decision tools. For this, more research on diagnostic imaging and validated values of bone loss indicating specific surgical treatment is needed. 


\section{Appendix: shoulder instability survey}

Shoulder Instability Survey

Name:

Country:

1) How many shoulder instability patients do you see each year?

___ Patients

2) How many do you operate on?

_ Patients

3) Which anamnestic questions do you ask in any case?

$\square$ What is your profession?

$\square \quad$ What sports do you practice?

$\square$ Has a trauma occurred?

$\square$ How many dislocations have there been since the trauma?

$\square$ With which movements do you suffer from it?

$\square$ What have you already tried to improve the symptoms?

$\square \quad$ Do you have pain?

4) Which instability tests do you perform?
$\square$ Sulcus sign test
$\square$ Relocation test
$\square$ Apprehension test
$\square$ Hyperabduction test (Gagey)
$\square$ Anterior slide test
$\square$ Other:

5) Which imaging modality do you use for instability patients?
$\square$ Blanco CT scan
$\square \quad$ Ultrasound
$\square$ Blanco MR scan
$\square$ AP X-ray
$\square$ CT arthrography
$\square$ Bernageau view
$\square \quad$ MR arthrography
$\square$ Velpeau view

6) Which surgeries do you perform on shoulder instability (depending on the diagnosis)?
$\square$ Arthroscopic labrum repair
$\square$ Trillat
$\square$ Latarjet procedure
$\square$ Open Bankart procedure
$\square \quad$ Putti platt
$\square$ Arthroscopic Latarjet
$\square \quad$ Open capsular shift

7) Do you follow certain guidelines in your decision tree?

$\square \quad$ ISIS rules

$\square$ Other:

$\square \quad$ No

8) Do you think that - in the literature and guidelines - there is sufficient knowledge about the decision method for an operative treatment of shoulder instability?

$\square$ Yes

$\square \quad$ No

9) Do you quantify the Hill Sachs defect and use to this to perform a remplissage?

$\square$ Yes

$\square \quad$ No

10) Are you training or planning to perform arthroscopic Latarjet in the future?

$\square$ Yes

$\square$ No

11) Do you measure glenoid bone loss?

$\square \quad$ Yes, on CT

$\square \quad$ Yes, on MR

$\square \quad$ No

12) If yes, at which percentage of bony loss of the glenoid do you change your approach from soft tissue (labrum/Bankart) to bony procedure (Latarjet)?

$\%$

13) How do you calculate the percentage of bone loss? Classification by:
$\square$ Sugaya
$\square \quad$ Index X
$\square \quad$ Itoy
$\square$ Hardy

Thank you for your participation in this study! 
Open Access This article is distributed under the terms of the Creative Commons Attribution 4.0 International License (http://crea tivecommons.org/licenses/by/4.0/), which permits unrestricted use, distribution, and reproduction in any medium, provided you give appropriate credit to the original author(s) and the source, provide a link to the Creative Commons license, and indicate if changes were made.

\section{References}

1. Bahk M, Keyurapan E, Tasaki A, Sauers EL, McFarland EG (2007) Laxity testing of the shoulder: a review. Am J Sports Med 35(1):131-144

2. Balg F, Boileau P (2007) The instability severity index score. A simple pre-operative score to select patients for arthroscopic or open shoulder stabilisation. J Bone Joint Surg $\mathrm{Br}$ 89(11):1470-1477

3. Boileau P, Villalba M, Héry JY, Balg F, Ahrens P, Neyton L (2006) Risk factors for recurrence of shoulder instability after arthroscopic Bankart repair. J Bone Joint Surg Am 88(8):1755-1763

4. Boileau P, Thélu CÉ, Mercier N, Ohl X, Houghton-Clemmey R, Carles M, Trojani C (2014) Arthroscopic Bristow-Latarjet combined with Bankart repair restores shoulder stability in patients with glenoid bone loss. Clin Orthop Relat Res 472(8):2413-2424

5. Burkhart SS, De Beer JF (2000) Traumatic glenohumeral bone defects and their relationship to failure of arthroscopic Bankart repairs: significance of the inverted-pear glenoid and the humeral engaging Hill-Sachs lesion. Arthroscopy 16(7):677-694

6. Chalmers PN, Mascarenhas R, Leroux T, Sayegh ET, Verma NN, Cole BJ, Romeo AA (2015) Do arthroscopic and open stabilization techniques restore equivalent stability to the shoulder in the setting of anterior glenohumeral instability? A systematic review of overlapping meta-analyses. Arthroscopy 31(2):355-363

7. Dumont GD, Fogerty S, Rosso C, Lafosse L (2014) The arthroscopic Latarjet procedure for anterior shoulder instability: 5-year minimum follow-up. Am J Sports Med 42(11):2560-2566

8. Grumet RC, Bach BR Jr, Provencher MT (2010) Arthroscopic stabilization for first-time versus recurrent shoulder instability. Arthroscopy 26(2):239-248

9. Hobby J, Griffin D, Dunbar M, Boileau P (2007) Is arthroscopic surgery for stabilisation of chronic shoulder instability as effective as open surgery? A systematic review and meta-analysis of 62 studies including 3044 arthroscopic operations. J Bone Joint Surg Br 89(9):1188-1196

10. Hovelius L, Augustini BG, Fredin H, Johansson O, Norlin R, Thorling J (1996) Primary anterior dislocation of the shoulder in young patients. A ten-year prospective study. J Bone Joint Surg Am 78(11):1677-1684

11. Itoi E, Lee SB, Amrami KK, Wenger DE, An KN (2003) Quantitative assessment of classic anteroinferior bony Bankart lesions by radiography and computed tomography. Am J Sports Med 31(1):112-118

12. Lenters TR, Franta AK, Wolf FM, Leopold SS, Matsen FA (2007) Arthroscopic compared with open repairs for recurrent anterior shoulder instability. A systematic review and metaanalysis of the literature. J Bone Joint Surg Am 89(2):244-254

13. Lo IKY, Nonweiler B, Woolfrey M, Litchfield R, Kirkley A (2004) An evaluation of the apprehension, relocation, and surprise tests for anterior shoulder instability. Am J Sports Med 32:301-307

14. Longo UG, Loppini M, Rizzello G, Ciuffreda M, Maffulli N, Denaro V (2014) Management of primary acute anterior shoulder dislocation: systematic review and quantitative synthesis of the literature. Arthroscopy 30(4):506-522

15. Longo UG, Loppini M, Rizzello G, Romeo G, Huijsmans PE, Denaro V (2014) Glenoid and humeral head bone loss in traumatic anterior glenohumeral instability, a systematic review. Knee Surg Sports Traumatol Arthrosc 22(2):392-414

16. Luime JJ, Verhagen AP, Miedema HS, Kuiper JI, Burdorf A, Verhaar JA, Koes BW (2004) Does this patient have an instability of the shoulder or a labrum lesion? JAMA 292(16):1989-1999

17. Maqdes A, Chammai Y, Lengert R, Klouche S, Clavert P, Hardy P, Kempf JF (2015) The intra- and inter-observer reliability of the $\mathrm{CT}$-scan based $\mathrm{X}$ index to quantify glenoid bone loss in chronic anterior shoulder instability and its impact on decision making. Eur J Orthop Surg Traumatol 25(4):699-703

18. Olds M, Ellis R, Donaldson K, Parmar P, Kersten P (2015) Risk factors which predispose first-time traumatic anterior shoulder dislocations to recurrent instability in adults: a systematic review and meta-analysis. Br J Sports Med 49(14):913-922. doi:10. 1136/bjsports-2014-094342

19. Omori Y, Yamamoto N, Koishi H, Futai K, Goto A, Sugamoto K, Itoi $\mathrm{E}$ (2014) Measurement of the glenoid track in vivo as investigated by 3 -dimensional motion analysis using open MRI. Am J Sports Med 42(6):1290-1295

20. Pansard E, Klouche S, Billot N, Rousselin B, Kraus TM, Bauer T, Hardy P (2013) Reliability and validity assessment of a glenoid bone loss measurement using the Bernageau profile view in chronic anterior shoulder instability. J Shoulder Elbow Surg 22(9):1193-1198

21. Randelli P, Ragone V, Carminati S, Cabitza P (2012) Risk factors for recurrence after Bankart repair a systematic review. Knee Surg Sports Traumatol Arthrosc 20(11):2129-2138

22. Rashid MS, Crichton J, Butt U, Akimau PI, Charalambous CP (2014) Arthroscopic "Remplissage" for shoulder instability: a systematic review. Knee Surg Sports Traumatol Arthrosc 24(2):578-584

23. Sugaya H, Moriishi J, Dohi M, Kon Y, Tsuchiya A (2003) Glenoid rim morphology in recurrent anterior glenohumeral instability. J Bone Joint Surg Am 85-A(5):878-884

24. Thomazeau H, Courage O, Barth J, Pélégri C, Charousset C, Lespagnol F, Nourissat G, Audebert S, Guillo S, Toussaint B, Lafosse L, Bradel J, Veillard D, Boileau P, French Arthroscopy Society (2010) Can we improve the indication for Bankart arthroscopic repair? A preliminary clinical study using the ISIS score. Orthop Traumatol Surg Res 96(8 Suppl):S77-S83

25. Tzannes A, Paxinos A, Callanan M, Murrell GA (2004) An assessment of the interexaminer reliability of tests for shoulder instability. J Shoulder Elbow Surg 13(1):18-23

26. van der Linde JA, van Kampen DA, Terwee CB, Dijksman LM, Kleinjan G, Willems WJ (2011) Long-term results after arthroscopic shoulder stabilization using suture anchors: an 8- to 10-year follow-up. Am J Sports Med 39(11):2396-2403

27. van Kampen DA, van den Berg T, van der Woude HJ, Castelein RM, Terwee CB, Willems WJ (2013) Diagnostic value of patient characteristics, history, and six clinical tests for traumatic anterior shoulder instability. J Shoulder Elbow Surg 22(10):1310-1319

28. Yamamoto N, Itoi $\mathrm{E}$, Abe $\mathrm{H}$ et al (2007) Contact between the glenoid and the humeral head in abduction, external rotation, and horizontal extension: a new concept of glenoid track. J Shoulder Elbow Surg 16(5):649-656 